Review

\title{
Depictive and metric body size estimation in anorexia nervosa and bulimia nervosa: A systematic review and meta-analysis
}

\author{
Simone Claire Mölbert ${ }^{\mathrm{a}, \mathrm{b}, \mathrm{c}, \mathrm{d}, *}$, Lukas Klein ${ }^{\mathrm{a}}$, Anne Thaler ${ }^{\mathrm{b}, \mathrm{d}}$, Betty J. Mohler ${ }^{\mathrm{b}}$, Chiara Brozzo ${ }^{\mathrm{b}}$, \\ Peter Martus ${ }^{\mathrm{e}}$, Hans-Otto Karnath ${ }^{\mathrm{c}}$, Stephan Zipfel ${ }^{\mathrm{a}}$, Katrin Elisabeth Giel ${ }^{\mathrm{a}}$ \\ a Medical University Hospital Tübingen, Dpt. of Psychosomatic Medicine and Psychotherapy, Tübingen, Germany \\ b Max Planck Institute for Biological Cybernetics, Tübingen, Germany \\ c Center of Neurology, Division of Neuropsychology, University of Tübingen, Tübingen, Germany \\ d Graduate Training Centre of Neuroscience, International Max Planck Research School, University of Tübingen, Tübingen, Germany \\ e Institute for Epidemiology and Applied Biometry, University of Tübingen, Tübingen, Germany
}

\section{H I G H L I G H T S}

- Patients with Anorexia Nervosa and Bulimia Nervosa over-estimate their body with ES $=0.63$

- The degree of overestimation is moderated by the assessment method and patient diagnosis.

- We suggest a revised framework for BSE that integrates neuroscientific findings with previous models of body representation.

- Within this framework, we provide a clinical interpretation of body size overestimation.

\section{A R T I C L E I N F O}

\section{Keywords:}

Body image

Body size estimation

Anorexia nervosa

Bulimia nervosa

Eating disorders

\begin{abstract}
A B S T R A C T
A distorted representation of one's own body is a diagnostic criterion and core psychopathology of both anorexia nervosa ( $\mathrm{AN}$ ) and bulimia nervosa (BN). Despite recent technical advances in research, it is still unknown whether this body image disturbance is characterized by body dissatisfaction and a low ideal weight and/or includes a distorted perception or processing of body size. In this article, we provide an update and meta-analysis of 42 articles summarizing measures and results for body size estimation (BSE) from 926 individuals with AN, 536 individuals with BN and 1920 controls. We replicate findings that individuals with AN and BN overestimate their body size as compared to controls $(E S=0.63)$. Our meta-regression shows that metric methods (BSE by direct or indirect spatial measures) yield larger effect sizes than depictive methods (BSE by evaluating distorted pictures), and that effect sizes are larger for patients with BN than for patients with AN. To interpret these results, we suggest a revised theoretical framework for BSE that accounts for differences between depictive and metric BSE methods regarding the underlying body representations (conceptual vs. perceptual, implicit vs. explicit). We also discuss clinical implications and argue for the importance of multimethod approaches to investigate body image disturbance.
\end{abstract}

\section{Introduction}

A distorted representation of one's own body is a diagnostic criterion and core psychopathology of both anorexia nervosa (AN) and bulimia nervosa (BN) (American Psychiatric Association, 2013): despite being of a normal weight or even underweight, patients are convinced that they need to lose weight. This body image disturbance is considered to be a highly relevant factor for both AN and BN (Fairburn, Cooper, \& Shafran, 2003; Pennesi \& Wade, 2016; Tabri et al., 2015). Despite their relevance in research and clinical settings, the distinctive features of body image disturbance in AN and BN are still unknown. Specifically, it is unclear whether body image disturbance is characterized by body dissatisfaction in conjunction with a low ideal weight and/or includes distorted perception of one's own body size or the bodies of others.

Body size estimation (BSE) tasks were developed to investigate the perceptual component of how individuals perceive their body size, but have not yet yielded conclusive results. In this article, we provide an update and meta-analysis of the literature summarizing measures and results for body size estimations in AN and BN and suggest a revised

\footnotetext{
* Corresponding author at: Dpt. of Psychosomatic Medicine and Psychotherapy, Osianderstraße 5, 72076 Tübingen, Germany

E-mail address: simone.moelbert@med.uni-tuebingen.de (S.C. Mölbert).
} 
theoretical framework for BSE. Our revised framework additionally accounts for differences between depictive and metric BSE methods, and clarifies the clinical interpretation of their results.

\subsection{BSE as a research and clinical tool}

BSE tasks were developed in the 1960s and 1970s in pursuit of an objective measure of body perception suitable for the investigation of pathogenic mechanisms in AN (Slade \& Russell, 1973). In clinical settings, BSE is commonly used as a therapeutic tool or progress indicator. There are two distinct types of BSE methods to assess visual estimates of self-perceived body size: in depictive methods, participants estimate their body size based on individualized, weight-distorted mirror, photo or video images of their body in standard clothing. Typically, they are asked to select the correct option or adjust the body to their current or ideal body size. Usually, the whole body is presented, therefore depictive methods are also referred to as "whole body" methods (Cash \& Deagle, 1997; Farrell, Lee, \& Shafran, 2005; Gardner \& Brown, 2014). Until recently, depictive methods predominantly used optical distortion techniques, with the distortion often implemented as mere widening or squeezing of a photo in the horizontal dimension. More sophisticated and biometrically plausible distortion methods were developed only recently (Piryankova et al., 2014; Tovée, Benson, Emery, Mason, \& Cohen-Tovée, 2003).

In metric methods, participants estimate their size on a spatial measure by indicating the size of different body parts for example with a caliper, a rod or movable markers in a dedicated space in front of them (for example a wall). These distances are then taken in metric units, for example centimeters. In clinical settings, participants usually wear their own clothes and are not hindered from looking down at their body while doing the task, to make the task as naturalistic as possible. Unlike in depictive methods, participants do not express their judgments about pictures of their body, but reproduce their size as distances, with a focus on local spatial estimates and not on the global visual appearance of the body. While depictive methods use percent global distortion as outcome, outcomes in metric methods are measured in metric units, for example as shoulder, breast, or hips width in centimeters. It is customary, but not standard, to determine a whole body estimate as average of the different body part estimates; however, in contrast to depictive methods, this score represents an aggregate of several local estimates and not a global estimate. Therefore, composite whole body estimates may differ from whole body estimates as derived in depictive methods. Metric methods are also referred to as "body part methods" (Cash \& Deagle, 1997; Farrell et al., 2005; Gardner \& Brown,
2014). Table 1 provides an overview of different BSE methods.

The most commonly used outcome in BSE tasks is the body perception index (BPI) which is calculated according to the formula BPI = (estimated/actual body size) $\times 100$ (Slade \& Russell, 1973). Values below 100 indicate an underestimation and values above 100 indicate an overestimation in terms of percent of the actual body size. It is important to bear in mind that the BPI is a relative measure standardized to the individual's size; hence, the same absolute overestimation would result in a higher BPI when actual body size is smaller. However, switching to absolute units has not been found to improve the clarity of results (Smeets, Smit, Panhuysen, \& Ingleby, 1998).

On a theoretical level, BSE tasks have so far usually been discussed in the context of the "dual model" framework of body representations (Cash \& Deagle, 1997; Farrell et al., 2005; Gardner \& Brown, 2014). Generally, models in this framework distinguish between an actionserving representation often labeled as body schema and a representation serving perception of the own physical appearance, attitudes towards one's body and conceptual issues, often called body image (de Vignemont, 2010). As yet, BSE research has generally been motivated by the assumption that a perceptual distortion of body image, namely an overestimation of the self-perceived body size in the mental picture of the own body, may foster body dissatisfaction and may be a pathology mechanism of AN and BN (Farrell et al., 2005; Gardner, 1996; Gardner \& Brown, 2014).

A major flaw of this framework is the inconsistency in how different models belonging to it conceptualize body image and interpret BSE: some authors, typically in neurology and cognitive neuroscience, define body image as a mental picture of the body and thereby mainly perceptual (Paillard, 1999). Others, typically in the eating disorder literature, suggested a sub-division into a perceptual and an attitudinal component (Gadsby, 2017; Gardner \& Bokenkamp, 1996), or even in a system of perceptual component, attitudinal component and cognitions (Gaudio \& Quattrocchi, 2012). Consequently, BSE was usually interpreted as being indicative for a perceptual distortion, although this was not properly defined and several studies suggested there might not be a perceptual distortion at all (Fernandez-Aranda, Dahme, \& Meermann, 1999; Gardner \& Bokenkamp, 1996; Smeets, 1997; Smeets, Klugkist, van Rooden, Anema, \& Postma, 2009). Generally, suitability of the "dual model" framework as appropriate structure for studying body representation has been questioned (de Vignemont, 2010). To overcome this conceptual confusion, this study re-analyzes previous studies within an updated theoretical framework (Longo, 2015, 2016; Longo, Azañón, \& Haggard, 2010) that is sensitive to the aforementioned distinction between perceptual and attitudinal components of body

Table 1

Overview on methods used in included studies.

\begin{tabular}{|c|c|c|c|c|}
\hline Method & Description & Size & $\begin{array}{l}\text { \# of included } \\
\text { studies }\end{array}$ & Example \\
\hline \multicolumn{5}{|l|}{ Metric methods } \\
\hline Image marking & $\begin{array}{l}\text { The width of body parts, typically shoulders, waist, hips is indicated by marking } \\
\text { their endpoints on a wallpaper }\end{array}$ & Lifesize & 8 & $\begin{array}{l}\text { Askevold (1975) } \\
\text { Uys and Wassenaar (1996) }\end{array}$ \\
\hline Movable markers & $\begin{array}{l}\text { The width of body parts, typically face, chest, waist and hips is indicated by } \\
\text { adjusting movable markers, such as light points or a caliper }\end{array}$ & Lifesize & 14 & $\begin{array}{l}\text { Slade and Russell (1973) } \\
\text { Mizes (1992) }\end{array}$ \\
\hline Tape measure & $\begin{array}{l}\text { The width or circumference of body parts is indicated by adjusting a tape measure } \\
\text { or rod to the estimated size }\end{array}$ & Lifesize & 2 & $\begin{array}{l}\text { Horne, Van Vactor, and Emerson } \\
\text { (1991) } \\
\text { Smeets et al. (2009) }\end{array}$ \\
\hline \multicolumn{5}{|c|}{ Depictive methods } \\
\hline Photo Distortion & $\begin{array}{l}\text { Distorted static photos of the participant in standard clothing are shown and the } \\
\text { participants choose or adjust the correct one, or answer whether the respective } \\
\text { photos are wider or thinner than themselves }\end{array}$ & $\begin{array}{l}\text { Screen to } \\
\text { lifesize }\end{array}$ & 11 & $\begin{array}{l}\text { Collins (1987) } \\
\text { Tovée et al. (2003) } \\
\text { Urdapilleta, Cheneau, Masse, and } \\
\text { Blanchet (2007) }\end{array}$ \\
\hline Video Distortion & $\begin{array}{l}\text { A video of the participants in standard clothing is taken and presented after optical } \\
\text { distortion. Some earlier studies distorted optically only using a distorting mirror. } \\
\text { Participants are typically asked to adjust their current size. }\end{array}$ & $\begin{array}{l}\text { Screen to } \\
\text { lifesize }\end{array}$ & 16 & $\begin{array}{l}\text { Smeets et al. (1999) } \\
\text { Probst, Vandereycken, van } \\
\text { Coppenolle, and Pieters (1995) } \\
\text { Touyz, Beumont, Collins, McCabe, } \\
\text { and Jupp (1984) }\end{array}$ \\
\hline
\end{tabular}


representation distortion, as well as to the extent to which the distorted body representations are implicit versus explicit.

\subsection{Previous BSE findings in patients with $A N$ and $B N$}

So far, empirical evidence on performance of patients with AN and $\mathrm{BN}$ in BSE tasks is very heterogeneous and partly inconclusive. In an earlier meta-analysis of measures assessing body image disturbance, a moderate overestimation effect in both AN and BN patients was found (Cash \& Deagle, 1997). Further, Cash and Deagle (1997) found larger effects for depictive methods than for metric methods. In a subsequent review, Farrell et al. (2005) replicated the overestimation finding, but due to the validity problems that they assigned to most methods, they concluded that the significance of this overestimation is unclear. Importantly, Farrell et al. (2005) emphasize that validity problems did not only concern technical challenges of the experimental setups limiting ecological validity, but also a lack of theoretical concepts about what exactly the different BSE tasks assess. It is obvious that BSE recruits not only size representations, but potentially also memory, proprioception, cognitions and so forth.

More recent reviews report that subsequent research focused on solving the problem of ecological validity by improving BSE assessment methods while conceptual problems of BSE remain unsolved. As Gardner and Brown (2014) report in a recent review focusing only on individuals with AN, advanced photo distortion technique was the most common assessment method in recent publications. While Gardner and Brown (2014) report a trend for more homogeneous results finding overestimation in adult individuals with AN, Legenbauer, Thiemann, and Vocks (2014), on the other hand, found very heterogeneous results for children and adolescents with AN. To our knowledge, there are no follow up reviews involving BN patients. In summary, while the moderate general effect of body size overestimation in individuals with AN and BN seems to be a robust finding, it is still unclear whether this originates from perceptual distortions of the self-perceived body size or from attitudinal processes. In the meantime, however, theoretical advances of body representation frameworks allow for a more differentiated conceptualization of BSE tasks, and comparisons of estimates in different conditions might reveal insights into the meaning of overestimation.

\subsection{Revisiting the theoretical framework of BSE}

Recently, Longo suggested a new framework of body representations that includes body image and body schema among multiple other body representations (Longo, 2015, 2016; Longo et al., 2010). This framework is based on a neuroscientific perspective and encompasses sensory processing as well as higher order concepts of and about the body. It comprises multiple distinct body representations that are informed by different sensory modalities and can be arranged along two orthogonal axes. One of these axes represents how perceptual versus conceptual the representation appears to be, thereby retaining the traditional notion of the dual model (Longo, 2015). According to the framework, body representations that were previously classified as body schema or perceptual body image are located at the perceptual end of the dimension, and summarized under the term "somatoperception". Representations in the cognitive-affective body image domain fall at the conceptual end of the continuum, and are summarized under the term "somatorepresentation". The second dimension specifies how implicit versus explicit the representation is, that is, how easily it can be accessed by conscious introspection. Notably, the model assumes that multiple body representations can be active at the same time, but may be recruited more or less by specific tasks.

Although Longo's framework was initially developed for research on somatosensory processing, the authors subsequently used and revised it for the investigation of BSE tasks. Longo and Haggard (2012) concluded that metric and depictive BSE methods differ in how implicit or explicit the recruited representations are: Depictive methods might address explicit representations, namely what the participants think their body looks like. Metric methods could be located in the middle of the continuum, because they may also recruit implicit representations of one's width, depth, length, like they are also used for motor action. In other words, although metric methods require participants to provide an explicit visual estimate of their body size, they may additionally recruit more implicit body representations, for example from proprioception. As a consequence, systematic differences in BSE between the methods could indicate whether overestimation is rather driven by distortions in explicit or in implicit representations.

Regarding the perceptual versus conceptual dimension, it is currently unclear where to locate depictive versus metric methods best within Longo's framework. Although Longo (2015b) defines the body image as a perceptual representation not influenced by attitudinal factors, it has already been shown that attitudes towards one's own body can influence size estimation differently in individuals with eating disorders compared to controls (Cash \& Deagle, 1997; Gardner, 1996; Hsu \& Sobkiewicz, 1991; McCabe, Ricciardelli, Sitaram, \& Mikhail, 2006; Smeets, Ingleby, Hoek, \& Panhuysen, 1999). Also, the focus of the instruction on the "felt" versus "known" size can influence size estimates (Bowden, Touyz, Rodriguez, Hensley, \& Beumont, 1989). Consequently, BSE tasks appear to assess a broad range of perceptual and conceptual representations, with the relative proportions remaining unclear in respect to study context and sample. For example, as physical appearance is central to the self-evaluation in individuals with eating disorders, BSE may activate more conceptual representations such as feelings and attitudes towards the body in individuals with AN and BN than in controls. Hence, the same BSE task could be more conceptual for individuals with an eating disorder than for healthy controls. Individuals with AN or BN would then overestimate their size not because they perceive the body differently, but because BSE in individuals with eating disorders assesses attitudes more than perception. Consequently, average differences in attitudes towards the body between different eating disorders should be reflected in BSE. Fig. 1 illustrates the classification of BSE tasks within this revised BSE framework.

\subsection{Objectives of the present study}

The present article aims to provide an updated review and metaanalysis on BSE tasks in both individuals with AN and BN. Unlike recent reviews, we integrate a meta-analysis of the results to investigate differences between the two eating disorders and between studies using depictive versus metric methods for estimating body size. Our

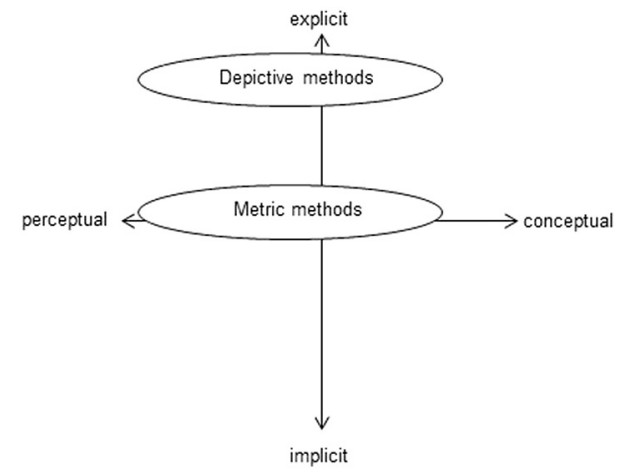

Fig. 1. The revised framework of BSE is based on a body model proposed by Longo (2016) in which two axes organize body representations depending on how perceptual or conceptual they are, and how implicit or explicit. Any given body representation will be located in a point in this space (for example perceptual and implicit). Each BSE task assesses multiple body representations. Depictive methods assess explicit representations only while metric methods assess explicit as well as implicit representations. Both methods are generally perceptual, but can target conceptual representations depending on the exact task specification and participant. 
objectives are to investigate a) whether patients with AN and BN overestimate their body size compared to control participants and how large the overall effect size is in current literature. Further, we use Longo's framework to investigate what type of body representations could drive mis-estimation in AN and BN by analyzing b) whether the degree of overestimation varies between patients with $\mathrm{AN}$ and $\mathrm{BN}$ and c) whether the degree of overestimation depends on the used method (depictive versus metric). In this context, we also consider to what extent the body representations involved in depictive vs. metric BSE are conceptual versus perceptual, and implicit versus explicit. We discuss implications for clinical practice and further research.

\section{Methods}

A systematic literature search was conducted according to PRISMA guidelines for systematic reviews and meta-analyses (Liberati et al., 2009; Moher, Liberati, Tetzlaff, \& Altman, 2009).

\subsection{Electronic searches}

We searched the databases PubMed and PsycInfo for literature published up to October 2016 on body schema or body image distortions. For PubMed, the search terms used in the general search were "body schema distorted/distortion/distortions" or "body schema size estimation". Since Medical Subject Headings (MeSH terms) for "body schema" were also included in the search, these keywords also covered combinations with the terms "body image" and "body representation". We narrowed the search to articles examining "Humans". The full search path for PubMed (not considering the restrictions) is [("body image"[MeSH Terms] OR ("body"[All Fields] AND "image"[All Fields]) OR "body image"[All Fields] OR ("body"[All Fields] AND "schema"[All Fields]) OR "body schema"[All Fields]) AND (distortion[All Fields] OR distorted[All Fields] OR distortions[All Fields]) OR (("body image"[MeSH Terms] OR ("body"[All Fields] AND "image"[All Fields]) OR "body image"[All Fields] OR ("body"[All Fields] AND "schema"[All Fields]) OR "body schema"[All Fields]) AND size[All Fields] AND estimation[All Fields])]. For PsycInfo, we used the equivalent search terms, using the Boolean search term [(body schema OR body image OR body representation) AND (distortion OR distorted OR distortions OR (size estimation))]. Again, we narrowed the search to human populations.

In addition, review articles were examined for relevant citations (Cash \& Deagle, 1997; Farrell et al., 2005; Gardner \& Brown, 2014), the Journal of Eating Disorders and Body Image were searched manually and The International Journal of Eating Disorders was searched manually from 1996 on to locate any additional studies.

\subsection{Eligibility criteria}

We included studies in the analysis if they met the following criteria: (1) Peer-reviewed journal article; (2) Language English, French or German; (3) Examination of adult individuals with AN or BN (no mixed eating disordered group) and control participants. AN or BN had to be defined according to classification systems that were up-to-date at the time of the study and controls had to be non-eating disordered; (4) reports results of a BSE task; (5) sample sizes, primary diagnosis, group mean of body perception index and standard deviation for whole body or body parts provided or derivable.

Studies were regarded as questionnaire surveys and not as BSE tasks if participants gave ratings on non-individualized material (as in figure rating tasks) or if the task was conducted as a structured interview in which predefined questions were read aloud and answers were recorded per to a predefined rating scheme. Methods were considered as BSE tasks if participants estimated their size based on their imagined own body or based on individually distorted visualizations of them. Reviews, meta-analyses, comments and letters to the editor were not included.

\subsection{Study selection procedure}

First, search results were imported into Endnote X7.1 and duplicates were removed. Afterwards, SCM and LK screened publications by title and abstract to remove articles that clearly did not meet eligibility criteria. At this step, we excluded articles only if both examiners assessed them to be irrelevant. Third, we obtained full texts of potentially relevant reports and both raters independently examined articles to determine whether they met eligibility criteria. Disagreements about study eligibility occurred for instance when due to complex study designs it was unclear which of the reported measures corresponded best to the measures reported in other studies. These disagreements were discussed and, if no immediate consensus was obtained, a third independent rater made a judgment about inclusion and rules were defined on which data to extract.

\subsection{Data collection}

We extracted the following data from the eligible studies: (1) sample sizes; (2) primary diagnose of patient sample; (3) type of BSE task used (depictive methods: photo or video distortion; metric methods: movable markers, tape measure, image marking); (4) mean BPI and standard deviations of each group for all reported body estimates. SCM and LK performed data extraction and data evaluation. In longitudinal and experimental studies, baseline performance was extracted. Some studies investigated the influence of different instructions on BSE (e.g. "How do you feel you look like?" versus "How do you think you look like?"). In these studies, we extracted the results for the most neutral instruction and if not applicable, for the most cognitively-focused instruction (i.e. for the "think" instruction and not for the "feel" instruction). In case of different control groups, the least preselected one was used (e.g. when anorexia nervosa patients were compared to restrained eaters and unrestrained eaters, values for unrestrained eaters were chosen). When a study examined several patient groups or used several methods, each of the group-wise comparisons for the respective methods and patient groups were extracted and all outcomes included into the analysis. If mean BPI and standard deviations for patient or control group were not explicitly reported but could be derived from the data provided (e.g. when raw data was presented or standard errors instead of standard deviations were reported), the authors performed calculations and the results were extracted.

Seven studies used metric methods and did not report a composite BPI for the whole body. While a post-hoc calculation of composite mean BPI could be performed based on the reported body part estimates, computation of the composite standard deviation was problematic: Computing the standard deviation of a sum of correlated terms requires knowledge of the correlations between the measures, in our case between the body part estimates. As most studies did not report correlations between body part estimates, a post-hoc calculation of whole body BPI was in part speculative. We still exploratively estimated these covariances based on pooled correlations between body part estimates for patient and control groups derived from all available correlation matrices (Button, Fransella, \& Slade, 1977; Pierloot \& Houben, 1978; Slade \& Russell, 1973). However, all studies used to estimate the correlations investigated patients with AN, used movable markers methods, and reported different correlations for patients with AN and controls, suggesting that it might not be justified to transfer correlations from one group to another. Out of the nine analyses without composite BPI, only four were alike, the other five ones analyzed patients with BN. Three out of these five studies additionally used different body sites and one even used another metric method. We therefore did not include these post-hoc whole body BPI estimates in the meta-analysis, but only exploratively re-ran the meta-analysis including them and presented the results in terms of a sensitivity analysis. 
Table 2

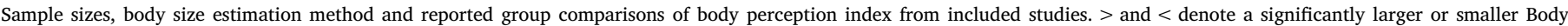

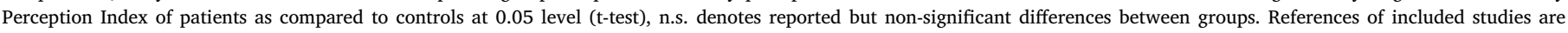
provided in Appendix (A).

\begin{tabular}{|c|c|c|c|c|c|c|c|c|c|c|}
\hline \multirow[t]{2}{*}{ Article } & \multirow{2}{*}{$\begin{array}{l}\text { nAN } \\
\text { patients }\end{array}$} & \multirow[t]{2}{*}{$\mathrm{nBN}$ patients } & \multirow[t]{2}{*}{ nControls } & \multirow{2}{*}{$\begin{array}{l}\text { Body size estimation } \\
\text { method }\end{array}$} & \multicolumn{6}{|c|}{ Patients' BPI compared to controls } \\
\hline & & & & & $\begin{array}{l}\text { Whole } \\
\text { body }\end{array}$ & Face & Shoulders & Chest & Waist & Hips \\
\hline Hagman et al. (2015) & 74 & & 11 & Photo distortion & $>$ & & & & & \\
\hline Øverås et al. (2014) & 37 & & 35 & Photo distortion & $>$ & & & & & \\
\hline Mohr et al. (2010) & 16 & & 16 & Photo distortion & n.s. & & & & & \\
\hline Schneider et al. (2009) & 75 & & 268 & Tape measure & $>$ & & & & n.s. & \\
\hline Urdapilleta et al. (2007) & 22 & & 22 & Photo distortion & n.s. & & & & & \\
\hline Vocks et al. (2007) & & 30 & 55 & Photo distortion & $>$ & & & & & \\
\hline \multirow[t]{2}{*}{ Tovée et al. (2003) } & 30 & & 137 & Photo distortion & n.s. & & & & & \\
\hline & & 30 & 137 & Photo distortion & n.s. & & & & & \\
\hline Smeets et al. (1999) & 30 & & 36 & Video distortion & $>$ & & & & & \\
\hline $\begin{array}{l}\text { Hennighausen, Enkelmann, Wewetzer, and } \\
\text { Remschmidt (1999) }\end{array}$ & 36 & & 18 & Photo distortion & n.s. & & & & & \\
\hline Kulbartz-Klatt, Florin, and Pook (1999) & & 40 & 40 & Video distortion & n.s. & & & & & \\
\hline Szymanski and Seime (1997) & & 20 & 20 & Video distortion & $>$ & & & & & \\
\hline \multirow[t]{3}{*}{ Probst, Vandereycken, and Van Coppenolle (1997) } & & 38 & 45 & Video distortion & $>$ & & & & & \\
\hline & 34 & & 45 & Video distortion & $>$ & & & & & \\
\hline & 87 & & 45 & Video distortion & n.s. & & & & & \\
\hline Uys and Wassenaar (1996) & 11 & & 51 & Image marking & n.s. & & n.s. & & $>$ & n.s. \\
\hline \multirow[t]{2}{*}{ Probst et al. (1995) } & 53 & & 36 & Video distortion & n.s. & & & & & \\
\hline & & 38 & 36 & Video distortion & n.s. & & & & & \\
\hline \multirow[t]{2}{*}{ Mizes (1992) } & 8 & & 11 & Movable markers & n.s. & & & & & \\
\hline & & 15 & 11 & Movable markers & n.s. & & & & & \\
\hline $\begin{array}{l}\text { Probst, Van Coppenolle, Vandereycken, and Goris } \\
\text { (1992) }\end{array}$ & 67 & & 105 & Video distortion & n.s. & & & & & \\
\hline Horne et al. (1991) & & 55 & 61 & Tape measure & $>$ & & & $>$ & $>$ & n.s. \\
\hline \multirow[t]{6}{*}{ Bowden et al. (1989) } & 12 & & 24 & Movable markers & $>$ & & & & & \\
\hline & 12 & & 24 & Image marking & $>$ & & & & & \\
\hline & 12 & & 24 & Video distortion & n.s. & & & & & \\
\hline & & 12 & 24 & Movable markers & n.s. & & & & & \\
\hline & & 12 & 24 & Image marking & $>$ & & & & & \\
\hline & & 12 & 24 & Video distortion & n.s. & & & & & \\
\hline Franzen, Florin, Schneider, and Meier (1988) & & 15 & 15 & Video distortion & n.s. & & & & & \\
\hline Lindholm and Wilson (1988) & & 12 & 12 & Video distortion & $>$ & & & & & \\
\hline Mizes (1988) & & 20 & 20 & Movable markers & $>$ & & & & & \\
\hline Nudelman, Rosen, and Leitenberg (1988) & & 20 & 20 & Movable markers & $>$ & & & & & \\
\hline Gardner and Moncrieff (1988) & 9 & & 9 & Video distortion & n.s. & & & & & \\
\hline \multirow[t]{2}{*}{ Whitehouse, Freeman, and Annandale (1988) } & 12 & & 20 & Image marking & n.s. & & n.s. & & $>$ & n.s. \\
\hline & 12 & & 20 & Video distortion & n.s. & & & & & \\
\hline Willmuth et al. (1988) & & 20 & 20 & Movable markers & $>$ & & & & & \\
\hline \multirow[t]{4}{*}{ Gleghorn, Penner, Powers, and Schulman (1987) } & & 55 & 55 & Photo distortion & $>$ & & & & & \\
\hline & & 55 & 55 & Image marking & & n.s. & $>$ & & $>$ & $>$ \\
\hline & & 55 & 55 & Movable markers & & n.s. & $>$ & & $>$ & $>$ \\
\hline & & 55 & 55 & Movable markers & & n.s. & $>$ & & $>$ & $>$ \\
\hline Collins (1987) & 25 & & 50 & Photo distortion & n.s. & & & & & \\
\hline Proctor and Morley (1986) & 24 & & 30 & Movable markers & & $>$ & & $>$ & $>$ & $>$ \\
\hline \multirow[t]{2}{*}{ Whitehouse, Freeman, and Annandale (1986) } & & 22 & 20 & Image marking & $>$ & & n.s. & & $>$ & $>$ \\
\hline & & 22 & 20 & Video distortion & $>$ & & & & & \\
\hline Willmuth et al. (1985) & & 20 & 20 & Movable markers & & & & $>$ & $>$ & $>$ \\
\hline Freeman et al. (1985) & & 24 & 33 & Video distortion & $>$ & & & & & \\
\hline Touyz et al. (1984) & 15 & & 15 & Video distortion & n.s. & & & & & \\
\hline Meermann (1983) & 36 & & 35 & image marking & n.s. & n.s. & n.s. & & n.s. & n.s. \\
\hline & 36 & & 35 & Video distortion & $>$ & $>$ & & & & \\
\hline Garfinkel et al. (1983) & 23 & & 12 & Video distortion & $>$ & & & & & \\
\hline Strober, Goldenberg, Green, and Saxon (1979) & 18 & & 24 & Image marking & n.s. & & n.s. & & n.s. & n.s. \\
\hline Casper, Halmi, Goldberg, Eckert, and Davis (1979) & 79 & & 130 & Movable markers & & n.s. & & n.s. & $>$ & \\
\hline $\begin{array}{l}\text { Garfinkel, Moldofsky, Garner, Stancer, and Coscina } \\
\text { (1978) }\end{array}$ & 26 & & 16 & Photo distortion & n.s. & & & & & \\
\hline Pierloot and Houben (1978) & 31 & & 20 & Image marking & $>$ & & n.s. & & $>$ & n.s. \\
\hline & 31 & & 20 & Movable markers & $>$ & $>$ & & & $>$ & $>$ \\
\hline Button et al. (1977) & 20 & & 16 & Movable markers & & n.s. & & n.s. & n.s. & n.s. \\
\hline Garner, Garfinkel, Stancer, and Moldofsky (1976) & 18 & & 16 & Photo distortion & $>$ & & & & & \\
\hline Slade and Russell (1973) & 14 & & 20 & Movable markers & & $>$ & & $>$ & $>$ & $>$ \\
\hline
\end{tabular}

\subsection{Analysis of single studies}

An overview of studies was obtained in a standardized way by computing Hedge's $g$ as a measure of effect size for each reported group comparison and performing t-tests to test whether the respective group comparisons were statistically significant. Study characteristics and main findings were then summarized in Table 2.

\subsection{Meta-analysis of studies reporting whole body BPI}

As listed in Table 2, 35 (86\%) of the studies reported BPI for the whole body, either directly derived (depictive methods) or as a 
composite score from body part estimates (metric methods). On these data, we performed a meta-analysis using $\mathrm{R}$ statistics software with package metafor (Viechtbauer, 2010). We accounted for clustered data structure using article as outer factor and assessment method (video distortion, photo distortion, image marking, movable markers, tape circumference) as inner factor. Following Borenstein, Hedges, Higgins, and Rothstein (2009) we tested: (a) whether patients overestimate their body size compared to control participants, (b) whether the degree of overestimation varies between patients with $\mathrm{AN}$ and $\mathrm{BN}$, and (c) whether accuracy of BSE depends on the method category used (depictive versus metric method). First, we performed a random effects metaanalysis to obtain a general estimate of overall effect size. In a second step, we performed a meta-regression using a random-effects model with "patient diagnosis" and "assessment method" as moderators to explore whether they are meaningful moderators of effect size. Additionally, we performed a random-effects meta-regression on BPI measures of control participants only using method category (depictive versus metric) as a moderator to check for baseline differences between the method categories, as suggested by Longo and Haggard (2012). In this analysis, we excluded double records due to multiple patient samples within one study, however modeled the clustered data structure with article as outer factor and assessment method as inner factor.

\section{Results}

\subsection{Study selection}

Our search in electronic databases yielded 1836 hits, 27 records were additionally identified through handed search. We eliminated 231 duplicates and discarded 1273 articles after reviewing title and abstract. The remaining studies were rated and 317 articles were excluded because they did not fulfil the eligibility criteria. 42 studies met all eligibility criteria and were included. Fig. 2 illustrates the study selection process in detail.

\subsection{Study characteristics}

Table 2 provides an overview of the included studies and their results. All included studies investigated women only. In recent years, photo distortion was the most commonly used method to assess BSE, continuing away from the trend of body part methods towards whole body methods. Generally, if studies found a significant difference between patient and control participant BPI, patients always had larger BPI compared to controls, supporting the overestimation findings of previous studies.

\subsection{Body part estimates}

Studies that used metric methods mostly investigated waist, hips, either shoulder or chest, and face width (Table 2). In 70\% of the metric studies, estimates were aggregated and a composite BPI score was reported for the whole body. Only six studies reported no BPI for the whole body, another study did not report a composite whole body BPI for body part methods, but provided a whole body estimate based on photo distortion. The most consistent significant difference between patient and control BPI was found for the waist, where $72 \%$ of group comparisons report a significant group difference. For the shoulder width, only $33 \%$ of group comparisons yielded a significant difference between patients' and controls' estimates. Pooled correlations between face, chest, waist and hips estimates ranged between $r=0.67$ and $r=0.85$ in individuals with AN and between $r=0.54$ and $r=0.84$ in controls, suggesting that generally, aggregation to a composite whole body BPI is justified. Shoulder size estimates, however, correlated more weakly with other body part estimates (between $r=0.50$ and $r=0.59$ in individuals with AN and between $r=0.25$ and $r=0.81$ in controls).

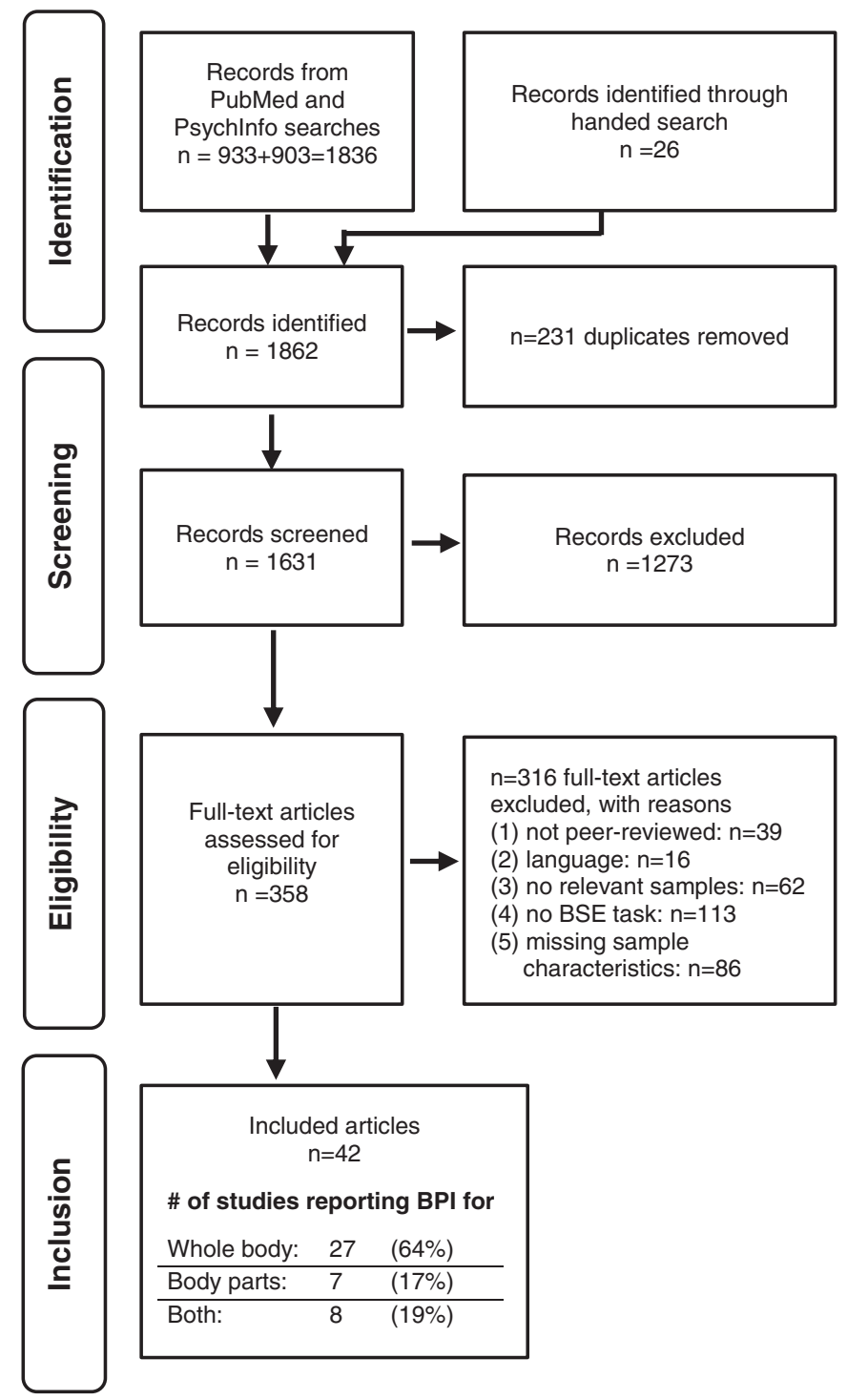

Fig. 2. PRISMA-Flowchart of the study selection procedure.

\subsection{Meta-Analysis of whole body BPI}

The random-effects model estimated the pooled effect size of all studies reporting group means of whole body BPI to be $E S=0.63$ ( $C I$ [0.49-0.78], $p<0.001$ ), which can be interpreted as an overall moderate effect in the sense that patients with $\mathrm{AN}$ and BN overestimate their body size as compared to controls. However, there was significant moderate heterogeneity in effect sizes $(Q(d f=49)=135.69$, $p<0.001)$, indicating that effect sizes vary systematically across the studies (Higgins, Thompson, Deeks, \& Altman, 2003).

As the meta-regression showed, the proposed moderators "patient diagnosis" and "assessment method category" accounted together for a significant proportion of heterogeneity among effect sizes in group comparisons $\left(Q_{M o d}(d f=2)=17.31, \quad p<0.001\right)$. Specifically, in comparison with studies investigating patients with AN and using a depictive method $\left(d_{A N_{-} d e p}=0.45, C I[0.28 ; 0.61], p<0.001\right)$, studies using a metric method yielded larger effect sizes $\left(\beta_{\text {metric }}=0.40, C I\right.$ [0.16; 0.63], $p<0.01$ ) and studies investigating patients with $\mathrm{BN}$ yielded larger effect sizes $\left(\beta_{B N}=0.21, C I\right.$ [0.03; 0.41], $\left.p<0.05\right)$. Interactions were not considered in the model. Residual heterogeneity in effect sizes was still moderate $\left(Q_{E}(d f=47)=94.91, p<0.001\right)$. The forest plot (Fig. 3) provides an overview about the effect sizes of the different studies and subgroups. The funnel plot (Fig. 4) shows a 


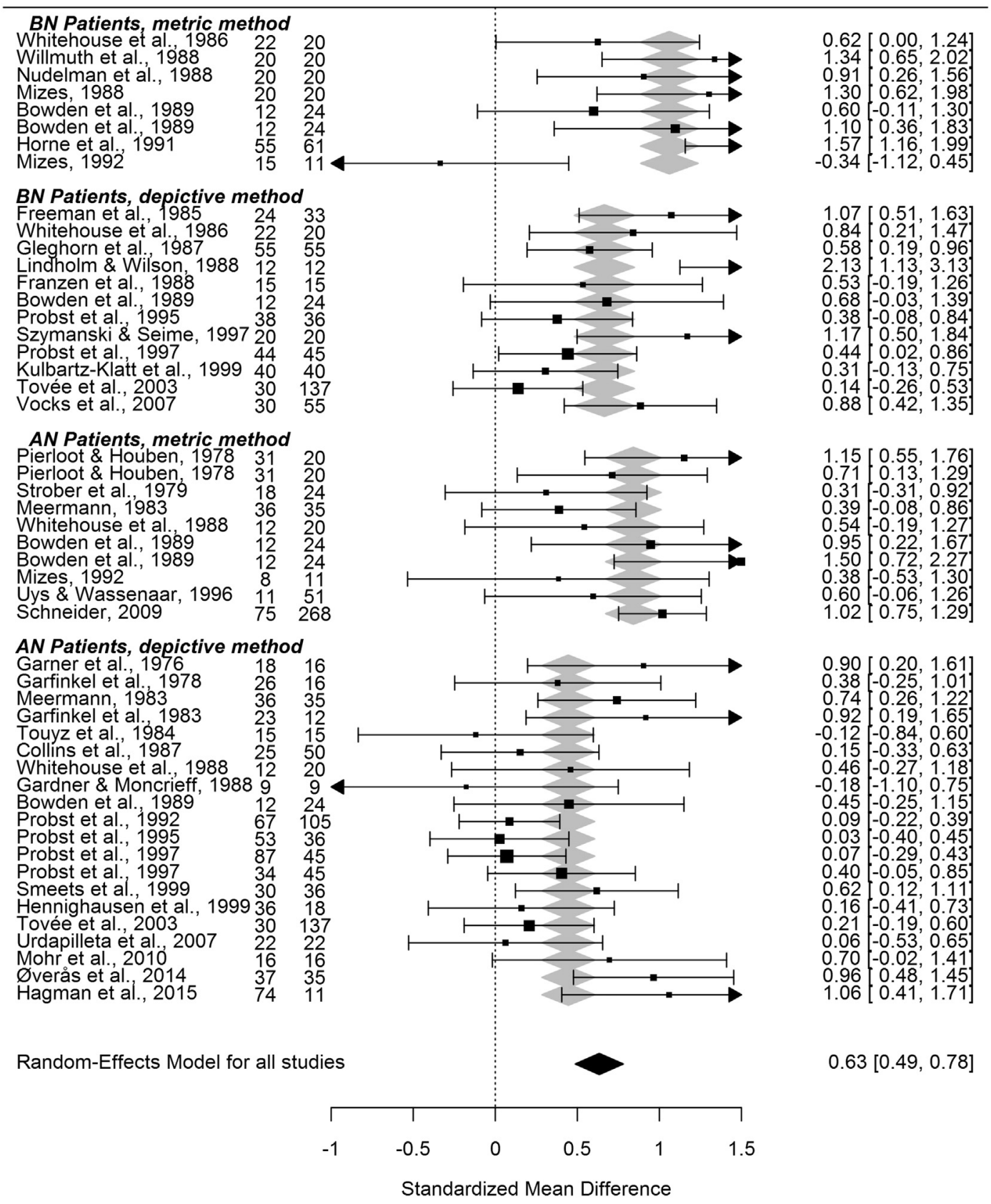

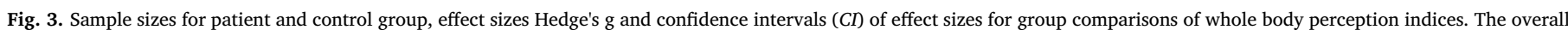

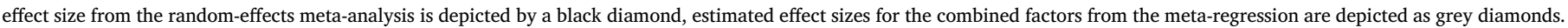

symmetric distribution of standard errors, indicating that publication bias is likely to be absent in the analyzed studies.

Two explorative meta-regressions were performed with post-hoc estimated composite whole body BPI for studies that had not reported whole body estimates. In a first step, we included only four additional studies that matched our data base for pooled correlations between body part estimates as they investigated individuals with AN and used movable markers as method. In this analysis, the overall effect increased to ES $=0.65$ ( $C I[0.50 ; 0.80])$ with no considerable change in moderator effects. In addition, we included five more data sets from two other studies investigating individuals with $\mathrm{BN}$, one of them with an image marking method. In this analysis, the overall effect size remained ES $=0.65$ ( $C I[0.50 ; 0.80])$, but the moderator effects were no longer significant (all $p>0.10$ ). Hence, while the overall effect size was very robust, the significance of the moderator effects was sensitive to the study selection.

Further, we analyzed the absolute BPI of control participants in a separate random effects meta-analysis and meta-regression. Through this, we obtained an average BPI for control participants, and could evaluate whether healthy people are also generally less accurate in metric methods than in explicit methods, as suggested by Longo and Haggard (2012).We found that on average, control participants are accurate in estimating their body size $\left(\mathrm{BPI}_{\mathrm{est}}=100.20, \mathrm{CI}\right.$ [94.40; 106.00], $Q(39)=12,266.56, p<0.001$ ). Assessment method category was a significant moderator of effect size. Confidence intervals of intercept and moderator weight show that already healthy people are accurate in depictive methods while they overestimate in metric methods $\left(\mathrm{BPI}_{\mathrm{dep}}=95.80, \mathrm{CI}[89.74 ; 101.86] ; \beta_{\text {metric }}=14.33, \mathrm{CI}[6.90\right.$; 


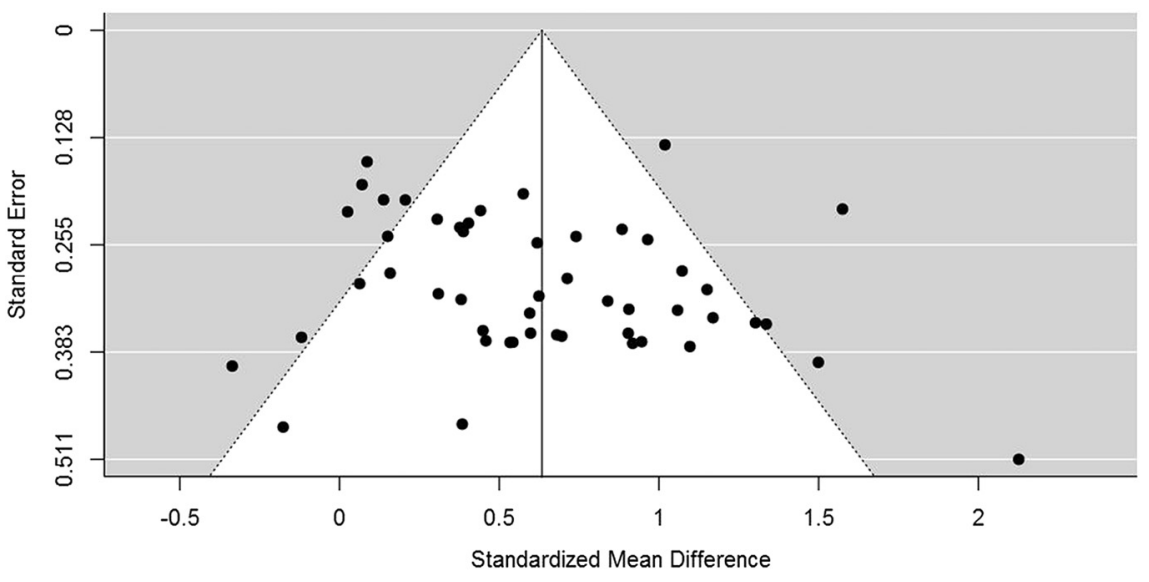

Fig. 4. Funnel plot for included studies.
21.75], $\quad p<0.001 ; \quad Q_{\mathrm{Mod}}(1)=14.28, \quad p<0.001$; $=11,153.30, p<0.001$ ).

\section{Discussion}

Like previous reviews, we observed a robust mean effect of $E S=0.63$ for whole body estimates, reflecting a moderate overestimation of self-perceived body size in individuals with AN and BN compared to controls (Cash \& Deagle, 1997; Farrell et al., 2005; Gardner \& Brown, 2014). Interestingly, our meta-regression shows that the factors "assessment method category" (depictive versus metric) and potentially "eating disorder diagnosis" (AN versus BN) significantly moderate effect sizes. Effect sizes were found to be larger in BN than in $\mathrm{AN}$, and self-perceived body size was overestimated more when metric methods were used than when depictive methods were used. Within the revised theoretical framework for BSE this suggests that body size overestimation is not driven by a perceptual distortion, but rather by distorted implicit representations and conceptual representations.

We used our meta-regression on controls' estimates to evaluate whether it is appropriate to transfer Longo and Haggard's (2012) considerations on classification of BSE tasks from hand size estimates to estimates of the whole body. Importantly, in our meta-regression of control participants' performance, we observed the same pattern that Longo and Haggard (2012) report for the hand size estimates: While in depictive methods, controls were accurate in estimating their size, we found controls to clearly overestimate in metric methods. As this replicates Longo and Haggard (2012), we conclude that metric methods likely assess not only explicit knowledge about the body size, but also implicit representations.

In our meta-regression of effect sizes from eating disorder versus control group comparisons, we found that metric assessment methods produce larger effect sizes than depictive methods. Following our revised framework, this indicates that body image disturbance may not be as much an issue of explicit body representation but rather of implicit body representation. This interpretation is in line with recent evidence showing impairments in somatosensory and proprioceptive tasks in individuals with AN. According to this research, individuals with AN and BN would have no visual misperception of their body, but difficulties in generating a coherent self-perceived body representation arising from distortions in more implicit representations (Case, Wilson, \& Ramachandran, 2012; Keizer et al., 2013; for a review see Gaudio, Brooks, \& Riva, 2014;).

Regarding the perceptual versus conceptual classification of body representation, we propose both the moderator effect of eating disorder diagnosis and the review of body part wise results from metric methods are informative. Given the broad confidence interval and the sensitivity analysis, we interpreted the moderator effect of eating disorder diagnosis carefully. We found no evidence that individuals with AN generally overestimate more than individuals with BN, as suggested by recent research (Cornelissen, Bester, Cairns, Tovée, \& Cornelissen, 2015; Cornelissen, Johns, \& Tovée, 2013; Moscone, Amorim, Le Scanff, \& Leconte, 2017). However, our results agree with this line of research insofar as we also conclude that visual perception is likely not generally disturbed in eating disorders. If individuals with BN were to overestimate more than individuals with AN, this would mirror findings on conceptual body representations, particularly attitudes. It has been shown that individuals with BN have higher drive for thinness and body dissatisfaction than individuals with restrictive AN (Garner, Olmsted, \& Polivy, 1983; Paul \& Thiel, 2005). Consistent with this hypothesis, we found that in metric methods, overestimation was most consistent for body parts that are emotionally salient for individuals with an eating disorder, such as the waist and hips. Moreover, it has been shown that in mirror scenarios, individuals with AN and BN have an attentional bias towards the body parts that they are least satisfied with compared to healthy controls (Tuschen-Caffier et al., 2015). We therefore consider it likely that conceptual representations (explicit or implicit), in the form of attitudes towards the body, influence BSE estimates, especially in individuals with an eating disorder.

\subsection{Methodological imitations}

Methodological limitations of this review arise from our study selection process as well as from the included studies. As we only searched for published results, a publication bias towards significant effects cannot be excluded. Although the funnel plot showed a symmetric distribution of effect sizes, our results could still be an overestimation of the true effect size. Moreover, our explorative meta-analysis with estimated composite whole body BPI for studies that did not report it suggested that the moderator effects of eating disorder diagnosis and method category might not be robust. Further, as terminology in the field is very heterogeneous, it is possible that despite our broad search strategy, we missed relevant articles. To encounter problems arising from study heterogeneity, we also limited our search to studies reporting their results in terms of BPI (or convertible), thereby excluding studies with different, but potentially related outcomes. Notably, some of the included studies had small sample sizes and may have been underpowered. In addition, procedures varied considerably in how they quantified the percentage of mis-estimation. For example, while many metric measures use average indicated width in centimeters, depictive methods can rely on optical properties or even pixel counts. Unfortunately, as studies were very heterogeneous in if and how they reported attitudes towards one's body, we were also not able to include attitudes as a potential moderator in our quantitative analysis. 


\subsection{Conclusions and further directions}

In this systematic review and meta-analysis, we replicated the finding that individuals with AN and BN overall moderately overestimate their body size $(E S=0.63)$, and observed that this effect is moderated by BSE assessment method and potentially by eating disorder diagnosis. To clarify the reasons behind this overestimation, we interpreted these results in the light of Longo's framework of body representation (Longo, 2015). According to this model, the traditional notion of BSE targeting the mental picture and visual perception of the body applies to depictive methods only, while metric methods may additionally assess more implicit representations.

Our meta-analysis emphasizes that while perceptual representations are plausibly involved in both depictive and metric body size estimation, it is not adequate to generally interpret body size estimates as measures of "perceptual distortion" or "visual distortion" (Cash \& Deagle, 1997; Farrell et al., 2005; Gardner \& Brown, 2014; Slade \& Russell, 1973). Rather, even the purportedly simple BSE tasks assess an integration of several body representations. It may depend on task characteristics, and also on the participants themselves as to which representations are targeted by the respective task. Hence, overestimation findings are unlikely to reflect only a disturbed visual body perception, as has been stated previously (Farrell et al., 2005; Gardner \& Brown, 2014). To better understand body image disturbance in $\mathrm{AN}$ and $\mathrm{BN}$, it is necessary to investigate the different types of body representation and their interplay in multi-method approaches.

In particular, as effect sizes were larger for metric methods, and in light of recent findings that suggest distorted implicit representations (Gaudio et al., 2014), we assume that within the perceptual component of body image disturbance, implicit body representations may be impaired to a larger extent than explicit body weight representation. Furthermore, we discussed that BSE is not a pure measure of body perception, but also involves conceptual representations such as attitudes towards the body.

We see a major challenge for further research in investigating which body representations are assessed by different tasks, and what role different body representations play in eating disorders. Specifically, regarding the perceptual component of body image disturbance, further research is needed that targets implicit body representation and how those representations interact with explicit perceptual and cognitiveaffective body representations. For example, combining BSE with tasks involving somatosensation, affordances, or actions (cf. Gaudio et al., 2014 for a review) could help to shed light on the interplay between different types of body representations and their disturbances in eating disorders.

The lack of adequate etiologies in eating disorders is considered a significant hurdle in the development of more effective therapies (Pennesi \& Wade, 2016; Schmidt \& Campbell, 2013). Specific exposure therapies targeting body perception have already been tentatively developed, but so far usually address body dissatisfaction, body checking, and avoidance (Koskina, Campbell, \& Schmidt, 2013). In pursuit of a mechanism-oriented psychotherapy, it is crucial to understand more about the contributions of a distorted mental image of the body and other, potentially implicit body representations to body image disturbance. In addition, it would benefit the field to better understand the relationships between distorted body representations and other cognitive and affective disturbances in eating disorders, such as social processing, reward processing and emotionality (Caglar-Nazali et al., 2014; Lavender et al., 2015; O'Hara, Campbell, \& Schmidt, 2015).

\section{Role of funding sources}

This work was funded by the Swiss Anorexia Nervosa Foundation Project Nr. 42-14 and by the Centre for Integrative Neuroscience Tübingen through the German Excellence Initiative (EXC307) PoolProjekt-2014-03. The funders had no role in the study design, collection, analysis or interpretation of the data, writing the manuscript, or the decision to submit the paper for publication.

\section{Contributors}

SCM and KEG designed the study and wrote the protocol. SCM and LK conducted literature searches and provided summaries of previous research studies. SCM and PM conducted the statistical analysis. SCM, AT and CB wrote the first draft of the manuscript and all authors contributed to and have approved the final manuscript.

\section{Conflict of interest}

All authors declare that they have no conflict of interest.

\section{Appendix A. Supplementary data}

Supplementary data to this article can be found online at http://dx. doi.org/10.1016/j.cpr.2017.08.005.

\section{References}

American Psychiatric Association (2013). Feeding and eating disorders. Diagnostic and Statistical Manual of Mental Disorders (DSM-5)(5th ed.). Washington, DChttp://dx.doi. org/10.1176/appi.books.9780890425596.dsm10.

Askevold, F. (1975). Measuring body image: Preliminary report on a new method. Psychotherapy and Psychosomatics, 26(2), 71-77.

Borenstein, M., Hedges, L. V., Higgins, J. P. T., \& Rothstein, H. R. (2009). Introduction to meta-analysis. Wiley.

Bowden, P. K., Touyz, S. W., Rodriguez, P. J., Hensley, R., \& Beumont, P. J. (1989). Distorting patient or distorting instrument? Body shape disturbance in patients with anorexia nervosa and bulimia. British Journal of Psychiatry, 155(2), 196-201. http:// dx.doi.org/10.1192/bjp.155.2.196.

Button, E. J., Fransella, F., \& Slade, P. D. (1977). A reappraisal of body perception disturbance in anorexia nervosa. Psychological Medicine, 7(2), 235-243. http://dx.doi. org/10.1017/S0033291700029317.

Caglar-Nazali, H. P., Corfield, F., Cardi, V., Ambwani, S., Leppanen, J., Olabintan, O., .. Treasure, J. (2014). A systematic review and meta-analysis of "Systems for Social Processes" in eating disorders. Neuroscience and Biobehavioral Reviews, 42, 55-92. http://dx.doi.org/10.1016/j.neubiorev.2013.12.002.

Case, L. K., Wilson, R. C., \& Ramachandran, V. S. (2012). Diminished size - Weight il lusion in anorexia nervosa: evidence for visuo-proprioceptive integration deflict. Experimental Brain Research, 79-87. http://dx.doi.org/10.1007/s00221-011-2974-7.

Cash, T. F., \& Deagle, E. A. (1997). The nature and extent of body-image disturbances in anorexia nervosa and bulimia nervosa: A meta-analysis. International Journal of Eating Disorders, 22(2), 107-125.

Casper, R. C., Halmi, K.a., Goldberg, S. C., Eckert, E. D., \& Davis, J. M. (1979). Disturbances in body image estimation as related to other characteristics and outcome in anorexia nervosa. British Journal of Psychiatry, 134(1), 60-66. http://dx.doi. org/10.1192/bjp.134.1.60.

Collins, J. K. (1987). Methodology for the objective measurement of body image. International Journal of Eating Disorders, 6(3), 393-399. http://dx.doi.org/10.1002/ 1098-108X(198705)6:3<393::AID-EAT2260060309> 3.0.CO;2-I.

Cornelissen, K. K., Bester, A., Cairns, P., Tovée, M. J., \& Cornelissen, P. L. (2015). The influence of personal BMI on body size estimations and sensitivity to body size change in anorexia spectrum disorders. Body Image, 13, 75-85. http://dx.doi.org/10. 1016/j.bodyim.2015.01.001.

Cornelissen, P. L., Johns, A., \& Tovée, M. J. (2013). Body size over-estimation in women with anorexia nervosa is not qualitatively different from female controls. Body Image, 10(1), 103-111. http://dx.doi.org/10.1016/j.bodyim.2012.09.003.

de Vignemont, F. (2010). Body schema and body image - pros and cons. Neuropsychologia, 48(3), 669-680. http://dx.doi.org/10.1016/j.neuropsychologia.2009.09.022.

Fairburn, C. G., Cooper, Z., \& Shafran, R. (2003). Cognitive behaviour therapy for eating disorders: A "transdiagnostic" theory and treatment. Behaviour Research and Therapy, 41, 509-528. http://dx.doi.org/10.1016/S0005-7967(02)00088-8.

Farrell, C., Lee, M., \& Shafran, R. (2005). Assessment of body size estimation: A review. European Eating Disorders Review, 13(2), 75-88.

Fernandez-Aranda, F., Dahme, B., \& Meermann, R. (1999). Body image in eating disorders and analysis of its relevance: A preliminary study. Journal of Psychosomatic Research, 47(5), 419-428.

Franzen, U., Florin, I., Schneider, S., \& Meier, M. (1988). Distorted body image in bulimic women. Journal of Psychosomatic Research, 32(4-5), 445-450. http://dx.doi.org/10. 1016/0022-3999(88)90028-1.

Freeman, R. J., Thomas, C. D., Solyom, L., Koopman, R. F., Ph, D., Thomas, C. D., ... Koopman, R. F. (1985). Clinical and personality correlates of body size overestimation in anorexia nervosa and bulimia nervosa. International Journal of Eating Disorders, 4(4), 439-456.

Gadsby, S. (2017). Distorted body representations in anorexia nervosa. Consciousness and Cognition, 51, 17-33. http://dx.doi.org/10.1016/j.concog.2017.02.015. 
Gardner, R. M. (1996). Methodological issues in assessment of the perceptual component of body image disturbance. British Journal of Psychology, 87(2), 327-337.

Gardner, R. M., \& Bokenkamp, E. D. (1996). The role of sensory and nonsensory factors in body size estimations of eating disorders subjects. Journal of Clinical Psychology, 52(1), 3-15.

Gardner, R. M., \& Brown, D. L. (2014). Body size estimation in anorexia nervosa: A brief review of findings from 2003 through 2013. Psychiatry Research, 219(3), 407-410. http://dx.doi.org/10.1016/j.psychres.2014.06.029.

Gardner, R. M., \& Moncrieff, C. (1988). Body image distortion in anorexics as a nonsensory phenomenon: A signal detection approach. Journal of Clinical Psychology, 44(2), 101-107.

Garfinkel, P. E., Garner, D. M., Rose, J., Darby, P. L., Brandes, J. S., O'Hanlon, J., \& Walsh, N. (1983). A comparison of characteristics in the families of patients with anorexia nervosa and normal controls. Psychological Medicine, 13(4), 821-828.

Garfinkel, P. E., Moldofsky, H., Garner, D. M., Stancer, H. C., \& Coscina, D. V. (1978). Body awareness in anorexia nervosa: Disturbances in body image and satiety. Psychosomatic Medicine, 40(6), 487-498. http://dx.doi.org/10.1097/00006842197810000-00004.

Garner, D. M., Garfinkel, P. E., Stancer, H. C., \& Moldofsky, H. (1976). Body image disturbances in anorexia nervosa and obesity. Psychosomatic Medicine, 38(5), 327-336. http://dx.doi.org/10.1097/00006842-197609000-00005.

Garner, D. M., Olmsted, M. P., \& Polivy, J. (1983). Development and validation of a multidimensional Eating Disorders Inventory for anorexia nervosa and bulimia. International Journal of Eating Disorders, 2(2), 15-34. http://dx.doi.org/10.1002/ 1098-108X(198321)2:2<15::AID-EAT2260020203>3.0.CO;2-6.

Gaudio, S., Brooks, S. J., \& Riva, G. (2014). Nonvisual multisensory impairment of body perception in anorexia nervosa: A systematic review of neuropsychological studies. PloS One, 9(10), e110087. http://dx.doi.org/10.1371/journal.pone.0110087.

Gaudio, S., \& Quattrocchi, C. C. (2012). Neural basis of a multidimensional model of body image distortion in anorexia nervosa. Neuroscience and Biobehavioral Reviews, 36(8), 1839-1847. http://dx.doi.org/10.1016/j.neubiorev.2012.05.003.

Gleghorn, A. A., Penner, L. A., Powers, P. A., \& Schulman, R. (1987). The psychometric properties of several measures of body image. Journal of Psychopathology and Behavioral Assessment, 9(2), 203-218. http://dx.doi.org/10.1007/BF00960575.

Hagman, J., Gardner, R. M., Brown, D. L., Gralla, J., Fier, J. M., \& Frank, G. K. W. (2015). Body size overestimation and its association with body mass index, body dissatisfaction, and drive for thinness in anorexia nervosa. Eating and Weight Disorders, 20, 449-455. http://dx.doi.org/10.1007/s40519-015-0193-0.

Hennighausen, K., Enkelmann, D., Wewetzer, C., \& Remschmidt, H. (1999). Body image distortion in anorexia nervosa: Is there really a perceptual deficit? European Child \& Adolescent Psychiatry, 8(3), 200-206.

Higgins, J. P. T., Thompson, S. G., Deeks, J. J., \& Altman, D. G. (2003). Measuring inconsistency in meta-analyses. BMJ [British Medical Journal], 327(7414), 557-560. http://dx.doi.org/10.1136/bmj.327.7414.557.

Horne, L. R., Van Vactor, J. C., \& Emerson, S. (1991). Disturbed body image in patients with eating disorders. The American Journal of Psychiatry, 148(2), 211-215.

Hsu, L. K. G., \& Sobkiewicz, T. A. (1991). Body image disturbance: Time to abandon the concept for eating disorders? International Journal of Eating Disorders, 10(1), 15-30. http://dx.doi.org/10.1002/1098-108X(199101)10:1 <15::AID-EAT2260100103>3. 0.CO;2-I.

Keizer, A., Smeets, M. A. M., Dijkerman, H. C., Uzunbajakau, S. A., van Elburg, A., \& Postma, A. (2013). Too fat to fit through the door: First evidence for disturbed bodyscaled action in anorexia nervosa during locomotion. PloS One, 8(5), e64602. http:// dx.doi.org/10.1371/journal.pone.0064602.

Koskina, A., Campbell, I. C., \& Schmidt, U. (2013). Exposure therapy in eating disorders revisited. Neuroscience and Biobehavioral Reviews, 37(2), 193-208. http://dx.doi.org/ 10.1016/j.neubiorev.2012.11.010.

Kulbartz-Klatt, Y. J., Florin, I., \& Pook, M. (1999). Bulimia nervosa: Mood changes do have an impact on body width estimation. British Journal of Clinical Psychology, 38(Pt 3), 279-287. http://dx.doi.org/10.1348/014466599162854.

Lavender, J. M., Wonderlich, S. A., Engel, S. G., Gordon, K. H., Kaye, W. H., \& Mitchell, J. E. (2015). Dimensions of emotion dysregulation in anorexia nervosa and bulimia nervosa: A conceptual review of the empirical literature. Clinical Psychology Review, 40, 111-122. http://dx.doi.org/10.1016/j.cpr.2015.05.010.

Legenbauer, T., Thiemann, P., \& Vocks, S. (2014). Body image disturbance in children and adolescents with eating disorders. Current evidence and future directions. Zeitschrift für Kinder- und Jugendpsychiatrie und Psychotherapie, 42(1), 51-59. http://dx.doi.org/ 10.1024/1422-4917/a000269.

Liberati, A., Altman, D. G., Tetzlaff, J., Mulrow, C., Gøtzsche, P. C., Ioannidis, J. P.a., ... Moher, D. (2009). The PRISMA statement for reporting systematic reviews and metaanalyses of studies that evaluate health care interventions: Explanation and elaboration. PLoS Medicine, 6(7), e1000100. http://dx.doi.org/10.1371/journal.pmed. 1000100 .

Lindholm, L., \& Wilson, G. T. (1988). Body image assessment in patients with bulimia nervosa and normal controls. International Journal of Eating Disorders, 7(4), 527-539.

Longo, M. R. (2015). Implicit and explicit body representations. European Psychologist, 20(1), 6-15. http://dx.doi.org/10.1027/1016-9040/a000198.

Longo, M. R. (2016). Types of body representation. In Y. Coello, \& M. H. Fischer (Vol. Eds.), Perceptual and emotional embodiment: Foundations of embodied cognition. Vol. I. Perceptual and emotional embodiment: Foundations of embodied cognition (pp. 117-134). Oxon/New York: Routledge/Taylor \& Francis Group. http://dx.doi.org/10.4324/ 9781315751979.

Longo, M. R., Azañón, E., \& Haggard, P. (2010). More than skin deep: Body representation beyond primary somatosensory cortex. Neuropsychologia, 48(3), 655-668. http://dx. doi.org/10.1016/j.neuropsychologia.2009.08.022.

Longo, M. R., \& Haggard, P. (2012). Implicit body representations and the conscious body image. Acta Psychologica, 141(2), 164-168. http://dx.doi.org/10.1016/j.actpsy. 2012.07.015.

McCabe, M. P., Ricciardelli, L. A., Sitaram, G., \& Mikhail, K. (2006). Accuracy of body size estimation: Role of biopsychosocial variables. Body Image, 3(2), 163-171.

Meermann, R. (1983). Experimental investigation of disturbances in body image estimation in anorexia nervosa patients, and ballet and gymnastics pupils. International Journal of Eating Disorders, 2(4), 91-100. http://dx.doi.org/10.1002/1098-108X (198322)2:4<91::AID-EAT2260020416>3.0.CO;2-Z.

Mizes, J. S. (1988). Personality characteristics of bulimic and non-eating- disordered female controls: A cognitive behavioral perspective. International Journal of Eating Disorders, 7(4), 541-550.

Mizes, J. S. (1992). The Body Image Detection Device versus subjective measures of weight dissatisfaction: A validity comparison. Addictive Behaviors, 17(2), 125-136. http://dx.doi.org/10.1016/0306-4603(92)90017-P.

Moher, D., Liberati, A., Tetzlaff, J., \& Altman, D. G. (2009). Preferred reporting items for systematic reviews and meta-analyses: The PRISMA statement. PLoS Medicine, 6(7), e1000097. http://dx.doi.org/10.1371/journal.pmed.1000097.

Mohr, H. M., Zimmermann, J., Röder, C., Lenz, C., Overbeck, G., \& Grabhorn, R. (2010) Separating two components of body image in anorexia nervosa using fMRI. Psychological Medicine, 40(9), 1519-1529. http://dx.doi.org/10.1017/ S0033291709991826.

Moscone, A.-L., Amorim, M.-A., Le Scanff, C., \& Leconte, P. (2017). A model-driven approach to studying dissociations between body size mental representations in anorexia nervosa. Body Image, 20, 40-48. http://dx.doi.org/10.1016/j.bodyim.2016.11. 003.

Nudelman, S., Rosen, J. C., \& Leitenberg, H. (1988). Dissimilarities in eating attitudes, body image distortion, depression, and self-esteem between high-intensity male runners and women with bulimia nervosa. International Journal of Eating Disorders, 7(5), 625-634. http://dx.doi.org/10.1002/1098-108X(198809)7:5 < 625::AIDEAT2260070506 > 3.0.CO;2-Q.

O'Hara, C. B., Campbell, I. C., \& Schmidt, U. (2015). A reward-centred model of anorexia nervosa: A focussed narrative review of the neurological and psychophysiological literature. Neuroscience and Biobehavioral Reviews, 52, 131-152. http://dx.doi.org/10 1016/j.neubiorev.2015.02.012.

Øverås, M., Kapstad, H., Brunborg, C., Landrø, N. I., Lask, B., Overas, M., ... Lask, B. (2014). Memory versus perception of body size in patients with anorexia nervosa and healthy controls. European Eating Disorders Review, 22(2), 109-115. http://dx.doi. org/10.1002/erv.2276.

Paillard, J. (1999). Body schema and body image: A double dissociation in deafferented patients. In G. N. Gantchev, S. Mori, \& J. Massion (Eds.), Motor control, today and tomorrow (pp. 197-214). Sofia, Bulgaria: Academic Publishing House.

Paul, T., \& Thiel, A. (2005). Eating Disorder Inventory-2. Deutsche Version. Göttingen [u.a.]: Hogrefe.

Pennesi, J.-L., \& Wade, T. D. (2016). A systematic review of the existing models of disordered eating: Do they inform the development of effective interventions? Clinical Psychology Review, 43(June), 175-192. http://dx.doi.org/10.1016/j.cpr.2015.12. 004.

Pierloot, R. A., \& Houben, M. E. (1978). Estimation of body dimensions in anorexia nervosa. Psychological Medicine, 8(2), 317-324.

Piryankova, I. V., Stefanucci, J. K., Romero, J., De La Rosa, S., Black, M. J., \& Mohler, B. J. (2014). Can I recognize my body's weight? The influence of shape and texture on the perception of self. ACM Transactions on Applied Perception, 11(3), 1-18. http://dx.doi. org $/ 10.1145 / 2641568$.

Probst, M., Van Coppenolle, H., Vandereycken, W., \& Goris, M. (1992). Body image assessment in anorexia nervosa patients and university students by means of video distortion: A reliability study. Journal of Psychosomatic Research, 36(1), 89-97. http:// dx.doi.org/10.1016/0022-3999(92)90117-K.

Probst, M., Vandereycken, W., \& Van Coppenolle, H. (1997). Body-size estimation in eating disorders using video distortion on a life-size screen. Psychotherapy and Psychosomatics, 66(2), 87-91.

Probst, M., Vandereycken, W., van Coppenolle, H., \& Pieters, G. (1995). Body size estimation in eating disorder patients: Testing the video distortion method on a life-size screen. Behaviour Research and Therapy, 33(8), 985-990. http://dx.doi.org/10.1016/ 0005-7967(95)00037-X.

Proctor, L., \& Morley, S. (1986). "Demand characteristics" in body-size estimation in anorexia nervosa. The British Journal of Psychiatry, 149(1), 113-118. http://dx.doi. org/10.1192/bjp.149.1.113.

Schmidt, U., \& Campbell, I. C. (2013). Treatment of eating disorders cannot remain "brainless": The case for brain-directed treatments. European Eating Disorders Review, 21(6), 425-427. http://dx.doi.org/10.1002/erv.2257.

Schneider, N., Martus, P., Ehrlich, S., Pfeiffer, E., Lehmkuhl, U., \& Salbach-Andrae, H. (2009). The assessment of body image distortion in female adolescents with anorexia nervosa: The development of a Test for Body Image Distortion in Children and Adolescents (BID-CA). Eating and Weight Disorders, 14(2-3), e128-e136.

Slade, P. D., \& Russell, G. F. (1973). Awareness of body dimensions in anorexia nervosa: Cross-sectional and longitudinal studies. Psychological Medicine, 3, 188-199. http:// dx.doi.org/10.1017/S0033291700048510.

Smeets, M. A. M. (1997). The rise and fall of body size estimation research in anorexia nervosa: A review and reconceptualization. European Eating Disorders Review, 5(2), 75-95.

Smeets, M. A. M., Ingleby, J. D., Hoek, H. W., \& Panhuysen, G. E. M. (1999). Body size perception in anorexia nervosa: A signal detection approach. Journal of Psychosomatic Research, 46(5), 465-477.

Smeets, M. A. M., Klugkist, I. G., van Rooden, S., Anema, H. A., \& Postma, A. (2009). Mental body distance comparison: A tool for assessing clinical disturbances in visual body image. Acta Psychologica, 132(2), 157-165. http://dx.doi.org/10.1016/j.actpsy. 
2009.03.011.

Smeets, M. A. M., Smit, F., Panhuysen, G. E., \& Ingleby, J. D. (1998). Body perception index: Benefits, pitfalls, ideas. Journal of Psychosomatic Research, 44(3-4), 457-464.

Strober, M., Goldenberg, I., Green, J., \& Saxon, J. (1979). Body image disturbance in anorexia nervosa during the acute and recuperative phase. Psychological Medicine, 9(4), 695-701.

Szymanski, L.a., \& Seime, R. J. (1997). A re-examination of body image distortion: Evidence against a sensory explanation. International Journal of Eating Disorders, 21(2), 175-180.

Tabri, N., Murray, H. B., Thomas, J. J., Franko, D. L., Herzog, D. B., \& Eddy, K. T. (2015). Overvaluation of body shape/weight and engagement in non-compensatory weightcontrol behaviors in eating disorders: Is there a reciprocal relationship? Psychological Medicine, 1-8. http://dx.doi.org/10.1017/S0033291715000896.

Touyz, S. W., Beumont, P. J., Collins, J. K., McCabe, M., \& Jupp, J. (1984). Body shape perception and its disturbance in anorexia nervosa. The British Journal of Psychiatry, 144(2), 167-171. http://dx.doi.org/10.1192/bjp.144.2.167.

Tovée, M. J., Benson, P. J., Emery, J. L., Mason, S. M., \& Cohen-Tovée, E. M. (2003). Measurement of body size and shape perception in eating-disordered and control observers using body-shape software. British Journal of Psychology, 94(4), 501-516. http://dx.doi.org/10.1348/000712603322503060.

Tuschen-Caffier, B., Bender, C., Caffier, D., Klenner, K., Braks, K., \& Svaldi, J. (2015). Selective visual attention during mirror exposure in anorexia and bulimia nervosa PloS One, 10(12), e0145886. http://dx.doi.org/10.1371/journal.pone.0145886.
Urdapilleta, I., Cheneau, C., Masse, L., \& Blanchet, A. (2007). Comparative study of body image among dancers and anorexic girls. Eating and Weight Disorders, 12(3), 140-146.

Uys, D. C., \& Wassenaar, D. R. (1996). The perceptual and affective components of body image disturbances in anorexic and normal females. South Africa Journal of Psychology, 26(4), 236-242. http://dx.doi.org/10.1177/008124639602600406.

Viechtbauer, W. (2010). Conducting meta-analyses in R with the metafor package. Journal of Statistical Software, 36(3), 1-48. http://dx.doi.org/10.1103/PhysRevB.91. 121108.

Vocks, S., Legenbauer, T., Ruddel, H., Troje, N. F., Rüddel, H., \& Troje, N. F. (2007). Static and dynamic body image in bulimia nervosa: mental representation of body dimensions and biological motion patterns. International Journal of Eating Disorders, 40(1), 59-66. http://dx.doi.org/10.1002/eat.20336.

Whitehouse, A. M., Freeman, C. P., \& Annandale, A. (1986). Body size estimation in bulimia. British Journal of Psychiatry, 149(1), 98-103. http://dx.doi.org/10.1192/bjp. 149.1.98.

Whitehouse, A. M., Freeman, C. P., \& Annandale, A. (1988). Body size estimation in anorexia nervosa. British Journal of Psychiatry, 153(2), 23-26.

Willmuth, M. E., Fondacaro, K. M., Gross, J., Leitenberg, H., Rosen, J. C., Ph, D., ... Gross, J. (1985). Body size distortion in bulimia nervosa. International Journal of Eating Disorders, 4(1), 71-78.

Willmuth, M. E., Leitenberg, H., Rosen, J. C., Cado, S., Ph, D., Leitenberg, H., ... Cado, S. (1988). A comparison of purging and nonpurging normal weight bulimics. International Journal of Eating Disorders, 7(6), 825-835. 